\title{
La peste del tirano Edipo: política, medicina y desmesura
}

\section{The Tyrant Oedipus Plage: Politics, Medicine, and Excess}

\author{
David García PÉREZ \\ https://orcid.org/0000-0001-5312-2544 \\ Instituto de Investigaciones Filológicas, Universidad Nacional Autónoma de México, México \\ hyperion0z@yahoo.com
}

RESUMEN: En este trabajo se expone la relación temática entre la política y la medicina que es posible discernir en el Edipo tirano de Sófocles. El hilo conductor entre ambas disciplinas ( $\tau \dot{\varepsilon} \chi v \propto l)$ es el concepto de desmesura (üß@ı) como causa de la peste que asoló la región del Ática en el 430 a. C., de acuerdo con la disposición trágica del mito de Edipo. Para tal fin, se recurre a Tucídides como fuente histórica, lo que permite un acercamiento a la tragedia de Sófocles desde la historiografía y, de este modo, se argumenta la configuración del Edipo como tirano; un concepto estrechamente enlazado con el tema de la pandemia referida.

Palabras Clave: Edipo, enfermedad, hybris, pandemia, Sófocles, tirano, Tucídides

ABSTRACT: This paper exposes the thematic relationship between politics and medicine which can be inferred from the Oedipus Tyranus by Sophocles. We can find the concept of excess (ن̈ßoıs) as a common thread between both arts ( $\tau \varepsilon \varepsilon^{\prime} \chi \sim \mathrm{l}$ ) as it is the cause of the wrecking plague in $430 \mathrm{BC}$ Attica, just as it is formulated in the Tragic version of Oedipus' myth. We resort to the History of Thucydides to help us approaching Sophocles' tragedy from historiography and, thus, configurating Oedipus as a tyrant, conception linked to the theme of the aforementioned plague.

Keywords: Oedipus, Disease, Hybris, Pandemic, Sophocles, Tyrant, Thucydides ReCiBIDO: 23/04/2020 • ACEPTADO: 07/05/2020 • VeRsión FinAL: 31/10/2020

En el segundo año de la guerra del Peloponeso (430 a. C.), una enfermedad (vóøos) desconocida y de dimensiones terribles sobrevino en Atenas y sus alrededores, cobrando la vida de miles de seres humanos. Tucídides cuenta 
con detalles precisos, en los que se combina la visión del historiador y la del médico, el posible origen y diseminación geográfica de la enfermedad, cómo atacaba el cuerpo, su evolución y conclusión. ${ }^{1}$ Es una descripción muy penetrante y plena de viveza que retrata la sintomatología de la enfermedad y las consecuencias sociales que diezmaron a la población del Ática. Al haber sido víctima de la epidemia, Tucídides vivió y analizó ese momento como un hecho histórico que incidía en la evolución de la guerra en curso entre las poleis, es decir, la narración de la peste o plaga $(\lambda o u \mu o ́ \varsigma)^{2}$ presenta una disposición de los hechos que atañe tanto al problema médico en sí, como a la situación humana en una dimensión historiográfica. ${ }^{3}$ Uno de estos rasgos se halla, en efecto, en el orden del relato: antes del pasaje en el que el historiador

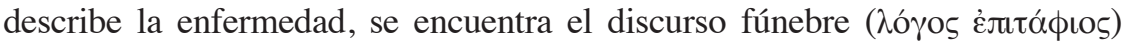
que Pericles, el célebre estratego ateniense, pronunció para honrar a los caídos en la guerra. El elogio de la democracia de Atenas, vertido en esta magnífica pieza oratoria, ${ }^{4}$ contrasta con el declive que produjo la peste que se cobró la vida misma de Pericles, quien falleció un año después. Poco antes de su muerte, este líder había pronunciado otro discurso en apoyo a su proyecto político-militar, en el que ya se atisba el deterioro mismo de la democracia ateniense. ${ }^{5}$ En medio de ambos discursos, la narración de la pandemia hecha por Tucídides parece marcar la ironía trágica con la que se desenvuelven los avatares humanos. El proyecto político y social de la polis democrática por antonomasia de pronto se vio modificado por una inesperada pandemia. ${ }^{6}$

\footnotetext{
${ }^{1}$ Th., II, 48-54.

2 Jouanna 2012, p. 124: "There is another type of disease that popular religious medicine connects with miasma: the general disease that descends on a city, which in Greek is called loimos. This is generally translated as 'plague', but should be translated, at least for the classical period, as 'pestilence', since the plague caused by Yersinia pestis does not seem to be known in this period. It is tragedy, not rational medicine, which informs us about the link between pestilence and miasma".

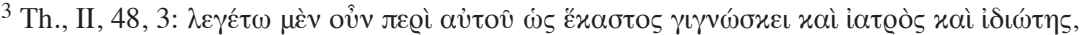

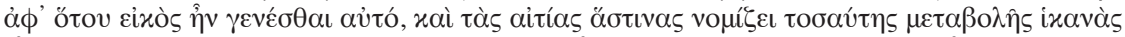

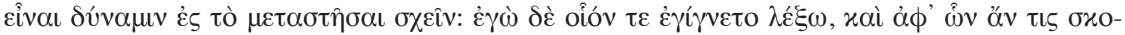

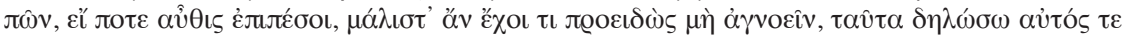

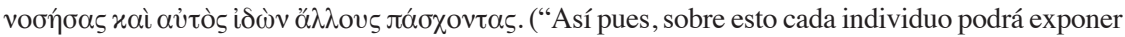
de acuerdo con su conocimiento, ya sea médico o lego, su posible origen y las causas por las que tan considerable cambio, a su entender, tal impulso tuvieron para originar aquel evento. Por lo que me concierne, contaré cómo se presentaba, y la observación de los síntomas, pues, en el caso de que nuevamente sobrevenga, habrá mejores condiciones para no equivocarse en la prevención, sabiéndolo de antemano; esto también lo demostraré porque yo mismo estuve enfermo y vi a otros que también la padecieron"). Todas las traducciones, salvo que se indique lo contrario, son propias.

${ }^{4}$ Th., II, 35-46.

${ }^{5}$ Th., II, 60-64.

${ }^{6}$ Cf. Alsina 1987, quien establece una interpretación literaria de la disposición tucidídea de los discursos de Pericles en relación con la descripción de la peste, en donde se integra la política con la medicina.
} 
Pues bien, es altamente probable que Sófocles escribiera y representara Edipo tirano inspirado en los acontecimientos de la peste aún vivos y que, en cierta manera, ${ }^{7}$ hubiera un eco de la suerte de Pericles en el personaje trágico y de la misma democracia ateniense. La materia de esta tragedia sofoclea yace en el mito de los Labdácidas, de modo que, ateniéndose a ello, la peste, así como otros motivos mitológicos, fueron innovaciones de Sófocles. Si esto fue así, la apertura del Edipo tirano en el teatro de Dionisos (c. 429 a. C.) no escatimó tiempo escénico para evidenciar la causa de la tragedia que los atenienses tuvieron oportunidad de apreciar como espectadores, pues ya en los primeros versos se describe a Tebas asolada completamente por una enfermedad perfilada como una sangrienta convulsión que hacía infecunda la tierra, el ganado y las mujeres. ${ }^{8}$ Ante esta situación, el pueblo acudió al gobernante para que ofreciera una solución a la "aborreci-

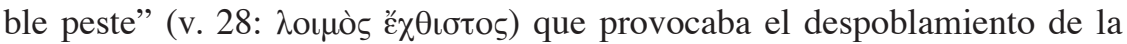
tierra Cadmea y nutría el Hades con sollozos y lamentos.

Edipo, además de ser el gobernante de Tebas, era visto como el médico que podía llevar a cabo el pronóstico de la enfermedad y, en consecuencia, recetar la cura. Esta visión sobre el tirano obedecía también a la fama de sabio que precedía a Edipo al haber vencido a la Esfinge con la resolución del célebre enigma: ¿quién es el ser que anda en cuatro pies, luego en dos y, por último, en tres? Al resolver el acertijo - el ser humano era tal ser-, Edipo venció al monstruo y liberó a los tebanos de su yugo. El planteamiento que se tiene, entonces, es el siguiente: los habitantes de Tebas son azotados por una peste que los está diezmando, el tirano es el médico y gobernante al mismo tiempo, y el propósito de éste radica en hallar, exponer y curar el origen de la enfermedad, mediante un proceso trágico que transita del plano público - los tebanos enfermos en actitud suplicante, esto es, como pacientes y como ciudadanos sujetos a la sabiduría y a la voluntad del tirano- a la esfera privada - el proceder equivocado de Edipo y de toda su parentela-, sólo para hallar en la desmesura (üßoıs) del poder una causa de la peste.

La tragedia griega, en general, estaba pensada para su representación frente a un público heterogéneo, de modo que el contenido ofrecía una dilatada cauda de interpretaciones, tal como se aprecia en las múltiples lecturas

${ }^{7}$ El consenso de los traductores y estudiosos de esta pieza de Sófocles en la lengua española es la de utilizar Edipo rey. Nuestra propuesta reside en emplear para los fines argumentativos de este trabajo la traducción Edipo tirano, tal como el lector lo podrá comprobar. No pretendemos ir en contra del consenso. En cuanto al uso de Edipo tirano hay por lo menos un caso en español: la traducción de Pedro Estala (Madrid, Imprenta de Sancha, 1793).

${ }^{8}$ S., OT., 1-77. Planteado el problema histórico y literario, en Edipo tirano se trueca el escenario al pasar de Atenas a Tebas, lo mismo sucede también con el personaje central al ser Edipo un reflejo parcial de Pericles. Así, la tragedia expuesta en el teatro de Dionisos proyecta las posibles conexiones del tema literario y de la historia fuera de Atenas: en Tebas, un espacio mitológico y ajeno a lo que ha venido sucediendo en torno a la época y al espacio de Pericles. 
del Edipo tirano que se han hecho a lo largo de la tradición clásica en Occidente. Una de tales exégesis, en efecto, tiene que ver con la desmesura en la práctica del poder y con una enfermedad que aparece repentinamente en la comunidad y que allí mismo puede tener una multiplicidad de explicaciones, tantas como reacciones físicas, actitudes éticas y comentarios científicos pueda haber. ${ }^{9}$ Uno de los focos para tal ejercicio reside en la ironía trágica que marca el ritmo del Edipo tirano: los enfermos acuden al médico, quien es, al mismo tiempo, la fuente de la peste, pues Edipo es el paciente cero, aunque es asintomático. Las manifestaciones físicas de la peste son evidentes y concretas en la población, mientras que Edipo parece ser inmune corporalmente al mal que él mismo ha diseminado. En el marco del desarrollo de la tragedia, el poeta logra dar la impresión de que el poder es lo que mantiene a Edipo a buen resguardo. Esta circunstancia concuerda con el hecho de que, políticamente, sucede una situación semejante en el personaje central: el hijo de Layo y de Yocasta no es un mal gobernante de acuerdo con su naturaleza; al contrario, el pueblo lo mira como el primero de los seres humanos en las cuestiones de la vida y cercano al juicio de los dioses. ${ }^{10}$ Es el destino, entonces, el que lo coloca como el origen de la enfermedad, lo cual se traduce en la situación de ingobernabilidad a causa de esto mismo y por su proceder tiránico ante la indefinición de su futuro familiar y político.

En el plano ético de las creencias religiosas que se pueden encontrar en esta tragedia, la relectura que Sófocles hizo del mito condensa las faltas de los Labdácidas, la familia de la que descendía nuestro personaje: la transgresión sexual y el incesto marcan el destino de Edipo, ${ }^{11}$ quien no debió nacer si sus padres, Layo y Yocasta, hubieran cumplido el oráculo que les prevenía de tener tal descendencia, pues, como se sabe, el hijo mataría a su padre, desposaría a su madre y con ella engendraría hijos. La desmesura del proceder errado de los padres de Edipo conduce, finalmente, a la tragedia

\footnotetext{
${ }^{9}$ La bibliografía es abundante y remitimos sólo al estudio de Segal 1993, en el que el autor analiza el contexto, la estructura, la proyección de Edipo, y expone una interpretación acerca del mito de este personaje trágico.

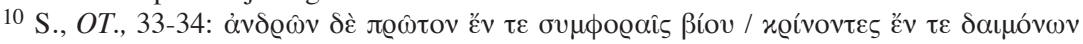

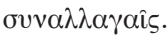

${ }^{11}$ La versión más conocida señala que Layo raptó a Crisipo, hijo de Pélope, cuando le enseñaba al joven a conducir el carro. Dicha acción implica una doble falta: por una parte, Layo violó el hospedaje ( $\xi \varepsilon v i ́ \alpha)$ que le prodigaba el hijo de Tántalo, lo cual era una ofensa también para los dioses, en especial para Zeus, patrono de esta institución; por otro lado, la pasión carnal que movió a Layo a realizar tal acción implica otra ofensa, pues el suicidio de Crisipo sería una prueba del rechazo a los requerimientos amorosos de Layo. De aquí proviene la maldición de Pélope a Layo: que jamás tuviera un hijo y, de llegarlo a tener, que se convirtiera en el asesino de su padre. Como consecuencia del nacimiento de Edipo, el incesto entre éste con su madre abona la tradición mítica en torno al error humano y al desconocimiento concreto de los hechos del destino tratado por Sófocles en Edipo tirano. Cf. Apollod., III, 5, 5; Epit., II, 3-9; Pi., O., I, 24-78; Hyg., Fab., 85; Kerényi 2009, pp. 120-122.
} 
concebida por Sófocles: la peste es producto de la mancha ( $\mu$ í $\alpha \mu \alpha$, como representación de la peste) que el asesino de Layo disemina en Tebas, pues el parricidio no fue castigado debidamente.

Esta concepción ético-religiosa se vincula con una interpretación política. La politiké téchne fue una de las teorías sociales más sobresalientes que los antiguos griegos generaron. La comprensión del individuo como parte de una comunidad regida por una serie de reglas que le permitían sobrevivir en medio de otros seres humanos definió las relaciones de la polis y los distintos modos de gobierno, en especial el de la democracia. Esta teoría coincidió con otras creaciones culturales del período clásico de la antigua Grecia, como el teatro y la medicina. ${ }^{12}$ Incluso se puede observar históricamente que la "invención" teatral acompañó la instauración de los postulados de la democracia ateniense y, en cierto modo, la coronación de este sistema político coincide con el esplendor de la tragedia y de la comedia. No es extraño, entonces, que el espacio teatral hiciera eco de los avatares políticos, y tampoco sorprende que la política tuviera mucho de teatralidad. Y hay que observar que, en ese momento histórico, el material temático del teatro acudía a la política como contexto y sus actores como representación de los problemas de la polis. Bien conocida es la postura de Aristófanes respecto de la demagógica democracia ateniense y los problemas que acarreaba a la polis un sistema sumamente burocrático; menos evidente es el juicio de la tragedia respecto de los mismos asuntos, debido a la prohibición de tratar temas contemporáneos que pusieran en entredicho la política vigente. ${ }^{13}$ Quizá por esta razón es que la tragedia está colmada de tiranos, entendido este término en la oscilación que define al rey, en general y como extensión del sátrapa oriental, y de una muy sutil referencia al gobernante absoluto, autoritario e

12 Jouanna 2012, p. 79: "Within this wide-ranging movement of the fifth century BC, 'when man freed himself from mythical thought in favour of rationalism', tragic poetry and the works of Hippocratic doctors are not at the same stage of development. The works of doctors are totally free from mythical thought, as is the work of the historian Thucydides, whilst the works of tragedians, since they take their material from myth, still remain indebted to archaic thought. This inherited thought is re-elaborated in tragedy according to the preoccupations and knowledge of the period. This explains the influence of Hippocratic medicine on some tragedies. Although Hippocratic medicine is more rational than Greek tragedy, we can say in contrast that Greek tragedy is more representative of the spirit of its time, since the age of Pericles is not only the age of the triumph of rationalism. The end of the fifth century is a paradoxical era, as it was not only the rational medicine of Hippocrates the Asclepiad that was flourishing, but also the miraculous medicine of the priests of the healing god Asclepius. Tragedy reminds us of this ambiguity of classical Greek thought, which risks being hidden by only reading rationalist writers such as the historian Thucydides or the doctor Hippocrates".

${ }^{13}$ Tal prohibición fue motivada, según la tradición, porque Frínico compuso la Ocupación de Mileto (494), donde trató un tema de política que le acarreó una multa al abordar la pérdida de Mileto en la guerra contra los persas. Hdt., VI, 21, 2. A partir de este evento, quedó prohibido para la tragedia el tratamiento de asuntos histórico-políticos vigentes. 
incapaz en comparación con otra figura de autoridad que no necesariamente era la del gobernante demócrata y que se representan oscilatoriamente en las tragedias griegas. ${ }^{14}$

Siendo esto así, en cuanto a Edipo tirano bastan dos evidencias al respecto: el espacio físico de la representación teatral en su sentido estrictamente estético fue una extensión de la plaza pública, pues lo que se dirimía en las asambleas populares se continuaba en las piezas dramáticas; en segundo lugar, no hay mejor representación del destino que aglutina el nudo trágico o la diatriba cómica que la del personaje político, en sentido amplio, pues por medio de la figura del gobernante se desplegaba en el escenario el tejido complicado de las máscaras pública y privada. Los avatares cotidianos del dirigente no están separados de su actuar político, pues esto obedece en muchas ocasiones a aquello que le sucede en su espacio familiar. En gran medida, las acciones equivocadas de los personajes trágicos, que de suyo conformaban la clase gobernante, tienen secuelas en el pueblo que sólo de vez en cuando se enuncian y en la mayoría de las ocasiones no se desconoce el resultado último. En el teatro griego, los papeles de los héroes se desenvolvían a través de estas dos vías que llegaban a ser una misma en la definición trágica: la vida del oikos era un ensayo dramático en la polis, igualmente de los foros de ésta - el teatro y el ágora-, y los ciudadanos eran los receptores tanto de la ficción dramática, como de la comprensión de la política. La tragedia no fue un texto políticamente aséptico por decreto, exento de indicios que condujeran a determinada respuesta que contraviniera el statu quo. Si bien es cierto que las tragedias acudían temáticamente a los viejos mitos de las grandes sagas familiares, o a las complejas relaciones entre dioses y hombres, o, incluso, a la destrucción y recomposición del cosmos, también lo es que tal tejido temático se sostiene sobre aquellos materiales prohibidos o censurados, dando como resultado una lectura que, entre la urdimbre y la trama, era una reflexión política de la polis en su aquí y ahora.

Teniendo en cuenta lo anterior, el título de Edipo tirano (Oidírous Túgavvos) parecería un sintagma elemental que indica a un personaje bastante conocido en la tradición mitológica de la antigua Grecia. Sin embargo, habría que considerar las connotaciones que este título tendría en los receptores de la Atenas democrática. Si bien es cierto que el término túgavvos designaría sin más al gobernante supremo, autónomo en cuanto que gobierna sólo con su voluntad, pero sin mayor trascendencia ideológica, también lo es que la tragedia habría contribuido a la configuración de un mal gobernante, opuesto a la práctica política de la democracia, sin que ello significara

\footnotetext{
${ }^{14}$ Obsérvese, por ejemplo, el caso de Zeus en el Prometeo encadenado de Esquilo, tragedia en la que el dios supremo es calificado reiteradamente como un gobernante nuevo, inexperto e injusto, entre otras cualidades que caen bajo el concepto de tirano. A., Pr., 34-35; 149-152.
} 
necesariamente una argumentación en favor de este régimen. En todo caso, la polisemia poética cumpliría con su cometido de crear interpretaciones distintas, tantas como variopinto era el público que asistía al recinto dionisiaco. Y no hay que perder de vista la conjunción del tiempo del mito con el tiempo real: Edipo como gobernante de la vieja aristocracia tebana que aparece como personaje en un teatro financiado por la polis democrática.

Desde el punto de vista existencial, la tragedia de Edipo tiene su raíz última en su propio nacimiento; este hecho es irrecusable e inherente a la voluntad de este personaje: la precisión del oráculo es diáfana al señalar que él no debía de nacer, porque de hacerlo sobrevendrían las acciones atinentes a su familia que acabarían con su linaje. El parricidio, el casamiento con su madre y la procreación con ésta de sus cuatro hijos/hermanos han sido analizados desde la psicología, la antropología y la mitología misma como representaciones de la evolución familiar y de la sociedad como fatalidades del destino. La saga de Edipo es la catástrofe familiar por antonomasia. Y Sófocles, a nuestro juicio, añade el ingrediente político que parte del problema de salud pública provocado por la peste, de manera que presenta en su tragedia a Edipo ya como gobernante de Tebas con plenitud de poderes, merced a que venció a la Esfinge y sus mortales adivinanzas para bien de ese pueblo, ${ }^{15}$ con un dominio nacido de su reconocida inteligencia y, por lo mismo, con una sabiduría que debía poner a prueba sus habilidades como tirano de la polis. Esto es, Sófocles dispone a su personaje en la órbita de las decisiones que debe de tomar en razón del estado que gobierna, en tanto que el pasado se proyecta como una sombra que irá descimbrando la trama de su destino. En este sentido, Yocasta, la madre-esposa de Edipo, parece más cuerda y lógica en su razonamiento frente a esa retrospección mitológica, más pragmática y, por lo tanto, con mejor vocación política que su propio hijo, al decirle a él que había que olvidar y desdeñar los oráculos por falsos. ${ }^{16}$ La racionalidad se encuentra, en ese momento de la Atenas de Pericles, en confrontación con el pensamiento mitológico y Sófocles hace eco de esa discusión en las palabras de Yocasta, teniendo como telón de fondo una catástrofe en la salud pública: ¿qué creer y a quién en momentos en los que la población cae muerta en las calles, si se atiene a la descripción de Tucídides?

Pues al no haber casas desocupadas y por habitar en barracas que eran asfixiantes por la época del año, sobrevino la mortandad en el más completo desorden, porque los cuerpos de los muertos estaban unos sobre de otros, mientras que los

15 Jouanna 2012, p. 60.

16 De acuerdo con Kerényi (2009, pp. 121-122) la vocación de madre-esposa de Yocasta hizo posible que su hermano Creonte gobernara Tebas y ya con Edipo convertido en gobernante su destino "era convertirse en la fuente del poder real". 
agonizantes se arrastraban por las calles y alrededor de las fuentes empujados por su deseo de agua. ${ }^{17}$

El tirano se define porque cree con una ciega certeza que la razón sólo le asiste a él. Se trata de una ceguera que es pandémica: como mácula $(\mu i \alpha \sigma \mu \alpha)$ que infecta a todo aquel con el que tiene contacto, el síntoma de la ceguera edípica se manifiesta en la polis por completo. La clave se encuentra en los vv. 95-98, cuando Creonte llega ante Edipo, luego de haber consultado el oráculo y le refiere que éste ha ordenado expulsar de Tebas al míasma causante de la enfermedad. Este término apunta directamente al campo de la medicina, según se colige de la presentación del Sacerdote que ha hablado en nombre del pueblo tebano para que su gobernante lo cure. Sin embargo, esta misma palabra, míasma, observada en la proyección del tema íntegro de la tragedia, lleva implícitos, según nuestra propuesta, los sentidos religioso y judicial. En cuanto a la significación religiosa, míasma deriva

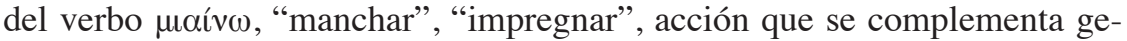
neralmente con el color púrpura; ${ }^{18}$ de esta construcción se habría originado la imagen de "teñir de rojo" para referirse, luego, a los delitos de sangre en el ámbito judicial. ${ }^{19}$ Ya en el siglo v, en la medicina y en la tragedia, míasma hace referencia a una enfermedad que se percibe por la sintomatología, por la evidencia física que puede apreciarse directamente, tal como hemos visto en las descripciones de Tucídides y de Sófocles.

Estas significaciones de míasma llegan al espacio político en el Edipo tirano: Sófocles representó la sintomatología que localiza la fuente del dolor que padece la polis y su gobernante en la ceguera como metáfora de la soberbia provocada por la sabiduría que llevó a Edipo a la soberanía. El gobernante enceguece de poder absoluto, pero en tal efecto la participación del pueblo es esencial. La apertura de la tragedia muestra con toda claridad cómo es que los tebanos acuden ante Edipo como su médico-gobernante, esto es, él tiene la obligación de curar al pueblo por partida doble, porque es él quien los gobierna y porque su sabiduría le da conocimientos específicos que Sófocles explica en metáforas médicas. Quien encumbra al tirano es el mismo pueblo. Ante la enfermedad y la muerte, Edipo aparece providencialmente como un hombre sabio que ahuyenta estas dolencias, y por lo tanto su supuesta sabiduría es lo que atrae a los tebanos que lo elevan como soberano absoluto, un grado menos que los dioses mismos. El nudo trágico se desliza

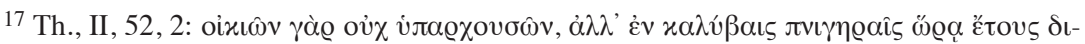

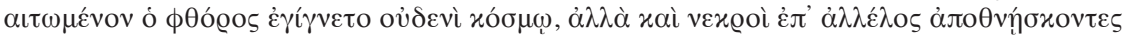

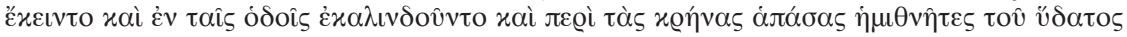

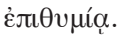

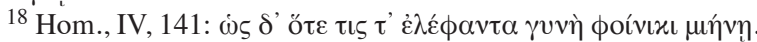

${ }^{19}$ Jouanna 2012, pp. 58 y 121-124. 
hacia el plano de la inteligencia, pero a pesar de que se reconoce esta cualidad, los personajes de Sófocles ignoran que en verdad no saben, y cuando se dan cuenta de la paradoja en la que han vivido ya no hay nada que remediar. ${ }^{20} \mathrm{Tal}$ conocimiento, como se demostrará, es mera ceguera que ataca al sujeto que cree poseer la respuesta a todos los males y que se encarna en todos aquellos que piensan que esa sabiduría es irrecusable; pero el nudo trágico en el que Edipo se ve atado es signo de la soledad en la que el tirano, el gobernante que dirige la nave del estado ciegamente, gobierna para sí como paradójica resolución de su poder absoluto. Como Edipo es la causa de la peste que azota Tebas y, en consecuencia, es al mismo tiempo el remedio, quedaría claro que, al ser castigado porque es el asesino de Layo, debería de abandonar el poder y la ciudad se salvaría, ${ }^{21}$ situación que no deja de ser otra paradoja, si atendemos la advertencia que el sacerdote le lanza a Edipo en relación con el hecho de que Tebas se va quedando despoblada a causa de la enfermedad:

Así pues, si gobernarás esta tierra como la gobiernas, / con hombres y no vacía es mejor que la gobiernes, / porque una nada es la fortaleza o la nave / desierta, al no haber hombres que las pueblen. ${ }^{22}$

Lo peor que le puede suceder a un gobernante es quedarse sin gobernados. Lo peor que le puede pasar al tirano es gobernar para sí mismo cuando sus decretos se vuelven en contra de su persona, o cuando su poder está tan desgastado que todo aquello que ordena cae en el vacío que él mismo ha provocado. En efecto, Edipo no sólo es ciego porque se arrancará los ojos como remedio al destino trágico que le tocó vivir, sino que lo es de nacimiento en un sentido ético y cósmico, hecho que marca su destino de manera indeleble porque más allá de que en su nombre, "el de los pies hinchados", lleva la marca de la herencia trágica que simboliza su origen y desgracia, es la hybris la que lo transforma en tirano y, en consecuencia, lo arrastra a su caída. Hecho, este último, que el gobernante acepta para liberar a su pueblo, por segunda vez, para que cese la enfermedad. Es muy probable que Sófocles fue quien revolucionó la historia de Edipo con el motivo de la ceguera, ${ }^{23}$ la cual relacionó con el concepto de la inteligencia. Es decir,

${ }^{20}$ Bañuls 2016, pp. 55, 58.

${ }^{21}$ Es de sumo interés la lectura de Detienne (2003, pp. 35-47) acerca de la limpieza étnica que puede estar inmersa en una situación como la de Edipo: el no ser autóctono, en sentido estricto, es una característica que se suma a la cadena de errores que llevan al tirano a la desgracia.

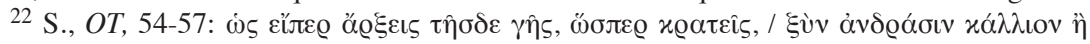

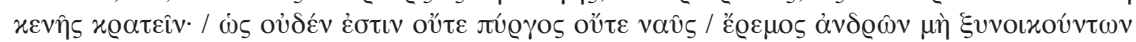

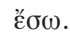

${ }^{23}$ Homero no menciona que Edipo sea ciego en la nekya, al encontrarse Odiseo con Epicasta: Od., IX, 271-280. En Il., XXII, 679, Homero sólo hace alusión a los funerales de Edipo. 
la mirada como correspondiente simbólico del saber para, de esta manera, subrayar que se trataba de una extirpación tanto física como intelectiva, y dentro de esta cuestión se halla también el aspecto político, como hemos venido exponiendo. No obstante, la actitud de Edipo contrasta con lo expresado por el Coro en el segundo stásimon, al reflexionar sobre las leyes divinas que son siempre las mismas y no envejecen, imagen que puede ser vista como premisa que se opone a la naturaleza del tirano. Edipo, en tanto que tirano, es producto de la soberbia que lo encumbra para dejarlo caer en la más profunda tragedia:

La desmesura engendra al tirano: / la desmesura, si se satura de muchas cosas en vano / que no son oportunas ni provechosas, / escalando a lo más alto, / de ahí se precipita hacia un abismo de desgracia, / donde no dispone de pie firme. / Pido que la divinidad nunca haga cesar/ la oposición que es favorable para la ciudad. ${ }^{24}$

Una cualidad que define el carácter dramático de Edipo tirano es el desarrollo del Coro a lo largo de la tragedia: si la pieza inicia con el pueblo como aliado y protegido del tirano, esto es, Tebas como aval político de su gobernante, con el paso de las acciones Edipo va quedando cada vez más solo. El derrumbe anunciado por el Coro en los versos 873-880 es síntoma de ello: la soberbia es quien engendra al tirano y es la responsable de su caída absoluta. Hay que subrayar que es el Coro quien coloca el dedo en la llaga al declarar que la desmesura es quien origina al tirano. Por ello aquellos que acompañaban a su gobernante poco a poco se irán retirando, alejándose de la mácula (míasma) que los protegía y que, en cierto modo, lo llevaron a las alturas para dejarlo abandonado en la caída. Los tebanos se curan de la peste y Edipo sale ciego al destierro. La imagen de treparse en el poder y perder la dimensión de la realidad tiene una exposición definitoria en esta intervención del Coro para referirse al tirano: este tipo de gobernante no alcanza a dimensionar que la desmesura (hybris) nacida en sus acciones y en sus palabras se opone a la justicia y a los dioses y, por lo

Hesíodo refiere la guerra de los siete contra Tebas sucintamente en Th., 161 ss. La Edipodia y la Tebaida tampoco aluden a un Edipo ciego. Así, la mayoría de las referencias al mito de Edipo en cuanto a la ceguera son tardías y tomadas de la tragedia de Sófocles.

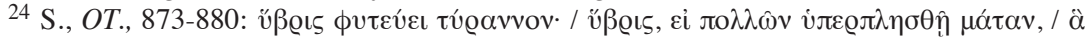

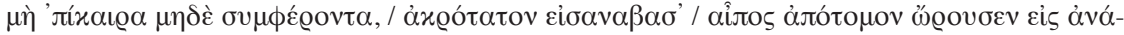

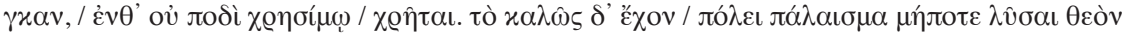

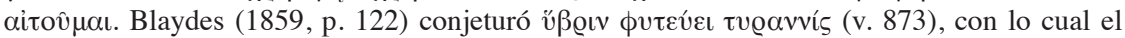
sentido es "la tiranía engendra la desmesura"; simplemente atribuyó el "error" en este verso al hecho de que el siguiente principia con la forma üßoıs.

Seguimos la lectura de Storr, que es la de los MSS. Para Scodel, la conjetura de Blaydes tendría un peso político mucho más fuerte, porque el tirano sería producto de su misma desmesura, lo que no obsta para que asimismo también la genere (1982, pp. 215-216). 
mismo, no es extraño que el destino funesto lo alcance, que las flechas de los dioses lo atraviesen (vv. 884-896). En el desarrollo dramático del Edipo tirano puede observarse que la empatía del Coro con el personaje principal no es absoluta, pues las reflexiones que aquél expresa van apartando la postura inicial trazada, de modo que queda en diáfana evidencia que el castigo por la soberbia es algo propio del tirano y no de los gobernados, pues éstos padecen la enfermedad únicamente porque comparten el espacio gobernado por dicho tirano. En efecto, en los versos con los que el Corifeo cierra la pieza trágica se hace explícito que el cúmulo de desgracias se cebó sobre Edipo, y eso es lo que debe observar Tebas, es decir, que esa suerte le corresponde a los desmesurados y, aquellos que no lo son, deben apartarse de esa enfermedad para no ser contaminados con la desgracia. ${ }^{25}$

A partir de Tucídides, se puede colegir que la tiranía es un proceso político en el cual el sujeto se ocupa sólo de lo que le es propio (tò ċ $\phi$ '

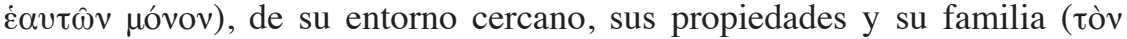
ísıv oîxov), y en consecuencia, no hace nada que sea digno de recordar en relación con el pueblo que gobierna. ${ }^{26} \mathrm{Si}$ bien Edipo arriba al poder de Tebas por derecho y por aclamación, hechos que por el destino constituyen un error de origen, la manera de gobernar unipersonalmente lo conduce a negar toda razón ajena a su pensamiento, aun cuando ésta procede de los dioses o de sus intermediarios, como el oráculo y Tiresias. Y a la negación de la sabiduría divina se suma la oposición política representada, de acuerdo con Edipo, por su cuñado Creonte. De este modo, el tirano deviene en un ser paranoico, pues todos se convierten en sus enemigos si se atreven a contradecir su palabra o si en ellos observa signos de deslealtad. ${ }^{27}$ Así, las advertencias de Tiresias, sustentadas en la sabiduría apolínea, ${ }^{28}$ son vistas por Edipo como una confabulación que llevaría a Creonte a ocupar el lugar del tirano, lo que se resuelve en una paradoja mediante la cual Sófocles ironiza sobre el pensamiento de quien se mira a sí mismo como gobernante absoluto cuando el propio Edipo argumenta desde su condición de tirano, tal como lo había indicado Creonte (vv. 514-515) al referirse a su cuñado como tirano:

¿Aquí tú? ¿Cómo puedes presentarte? ¿Tienes tal / audacia y el descaro de venir a mi casa, / tú que manifiestamente quieres ser mi asesino / y el usurpador de mi

${ }^{25} \mathrm{~S} .$, OT., 1516 ss.

${ }^{26}$ Th., I, 17,1 .

${ }^{27}$ Cf. Scodel 1982, pp. 218, 220: "The chorus expresses its political ideas by describing the hybris which creates a king, because, as applied to Oedipus, what is said is true: however his actions and those of Laius at their fateful meeting are to be judged. Oedipus became a monarch through hybris in the simple sese of aggressive violence".

${ }^{28}$ A diferencia de Creonte o de cualquier otro tebano, Tiresias es el único personaje que tiene libertad para confrontar a Edipo. Cf. S., OT., 410-411. 
tiranía? / ¡Vamos, habla, por los dioses! ¿Por un cobarde o por un demente / me has tomado y has resuelto llevar esto hasta el final? /

Ese proyecto, esa astucia de serpiente, / ¿suponías ignoraría, o que una vez descubiertas, no me defendería de ellas? / ¿No es empresa de un loco / buscar sin amigos, sin dinero, alzarse con el poder / que sólo puede obtenerse mediante las riquezas y por la voluntad del pueblo $?^{29}$

Frente a esta declaración y trayendo a colación nuevamente a Tucídides, salta a la vista aquello que el historiador menciona como cualidades del tirano que pueden ser aplicadas al personaje de Sófocles: conforme Edipo se va dando cuenta de la situación terrible en la que se encuentra, ya no se preocupa más de la peste que azota a Tebas; esta enfermedad es apenas el síntoma de un mal mayor que se asienta en la silla del poder. Para Edipo no es posible sospechar siquiera que él es el asesino de Layo, por ello entiende en las palabras del vidente un complot para sacarlo del poder $\mathrm{y}$, en consecuencia, de lo que se ocupa enseguida es de la defensa de su casa y de su gobierno. El tirano defiende lo indefendible, pues, como se sabe, llegó al poder de manera ilegal desde el punto de vista de la norma humana que prohíbe el parricidio así como el incesto y, sobre todo desde una cuestión del orden natural, por lo que aquello que cree ver como un plan para derrocarlo no es otra cosa que el temor de perder lo que obtuvo sin causa justificada; además de que se trata de un eslabón en la secuencia de un linaje marcado por un destino sumamente trágico a causa de la cadena de errores cometida, como él mismo lo reafirma sin saberlo, pues se asume como sustituto legal, no legítimo, de Layo, al recordar la continuidad del poder heredado: Agenor, Cadmo, Polidoro, Lábdaco, Layo y, para los espectadores que ya conocían el mito, Edipo (vv. 258-268), quienes además no darían crédito a las palabras del gobernante al ver cómo peligrosamente éstas lo van asediando a él mismo.

En efecto, el tirano es un gobernante ilegal desde diferentes puntos de vista. En el caso de Edipo se da la paradoja de que es y no es el heredero del trono tebano. Lo es porque es hijo de los reyes legítimos, y por lo tanto no sería llamado tirano, pero como él no lo sabe, llega a Tebas como extranjero

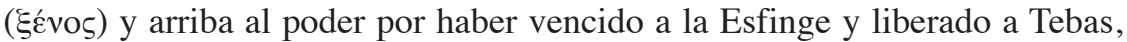
y por esto no puede ser visto como gobernante legítimo. Él mismo se denomina ciudadano tebano a partir de estos hechos fortuitos: "Mas ahora, al

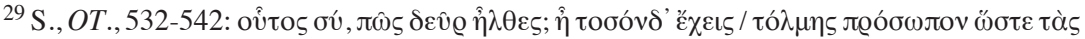

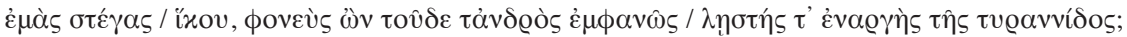

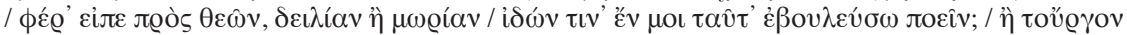

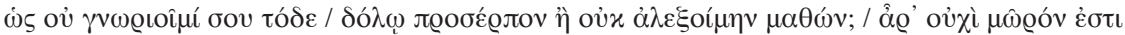

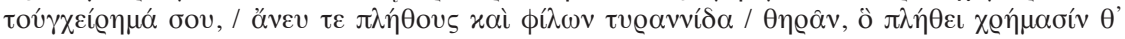
$\dot{\alpha} \lambda i ́ \sigma x \varepsilon \tau \alpha$. 
fin he llegado a ser un ciudadano entre ciudadanos". ${ }^{30}$ De igual manera, no puede ser improcedente el que Creonte hable de Layo como el dirigente (v. 103: $\dot{\gamma} \gamma \mu \omega \omega v)$ de Tebas hasta antes de la llegada de Edipo, y que éste, más adelante, califique como tiranía al gobierno de su padre, como si con ello corrigiera o delimitara las palabras de su tío-cuñado. ${ }^{31}$ Esta situación puede ser corroborada con la explicación de Tucídides: antes de la tiranía existió la monarquía que se heredaba de padres a hijos; el nuevo régimen fue producto del aumento de la riqueza que dio mucho poder a Grecia y se fue convirtiendo en una potencia marítima. ${ }^{32}$ En su Política, Aristóteles indica que la monarquía era el poder heredado, mientras que la tiranía no lo era. ${ }^{33}$ En razón de lo anterior, obsérvese cómo en el plano político la tragedia de Edipo coincide con el tránsito de la monarquía a la tiranía a través de la explicación del gobernante, de suyo ilegal, con la descripción de la tiranía en el contexto democrático en el que la tragedia de Sófocles fue representada, sin dejar de lado el ámbito mitológico de este personaje que se remonta a la poesía homérica. ${ }^{34}$ La paradoja que hemos señalado se resuelve en la anagnórisis del Coro, cuando descubre que Edipo es su rey legítimo, ${ }^{35}$ ya no es nombrado ni visto como tirano, pero la vuelta de tuerca para que funcione trágicamente se da demasiado tarde, pues la legitimidad significa al mismo tiempo la comprobación del contagio de la enfermedad que Edipo arrastra. ${ }^{36}$

Ahora bien, Sófocles describe el arribo de Edipo al trono tebano con una fuerte carga irónica que marca el modo de pensar de quien se sabe todopoderoso y conoce los alcances de su presencia, de manera que los receptores que ya conocían el mito debieron haber comprendido cabalmente el actuar improcedente del tirano, pues el intruso llegaba a ocupar la casa, la esposa, los potenciales hijos nacidos de un mismo padre y del pueblo entero. La ironía consiste en que la casa tomada por Edipo ciertamente es su casa, y llega a ella como un bastardo del destino, y si bien es innegable que arriba como "el más sabio entre todos" (v. 40) y como salvador de Tebas, en el fondo es tan ilegítimo como lo fue su nacimiento desde una posible interpretación del oráculo. Nació contra la voluntad divina y, por lo tanto, vivió de conformidad con esa afrenta que lo condujo a un destino pleno de desdicha.

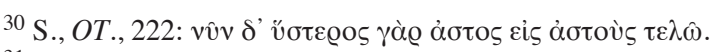

${ }^{31}$ S., OT., 128. En el vv. 799 y 1043, Edipo nuevamente llama tyrannos a su padre, pero en un contexto defensivo, esto es, buscando asimilar que aquel también fue tyrannos, como si en ello se pudiera matizar la cauda de errores cometidos por él.

${ }^{32}$ Cf. Th., I, 13, 1-2.

${ }^{33}$ Arist., Pol., 1285a, 1-3; 1312b, 21 ss.

${ }^{34}$ Hom., Il., IV, 378; XXIII, 679 ss., y sobre todo $O d$., XI, 271 ss.

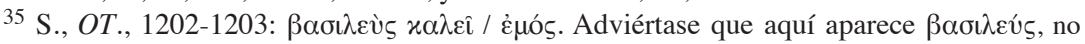
túgavvos.

${ }^{36}$ Cf. S., OT., 1378-1390. 
El problema de Edipo por esta vía interpretativa radica en la necedad que le hace creer que, sólo por ser quien es, la vida se resolvería según su voluntad.

Los decretos contra el asesino de Layo, emitidos por boca del mismo Edipo, son producto de la irreflexión, al punto de que se puede elucubrar que el triunfo sobre la Esfinge no es en sí resultado de una particular sabiduría que le asiste al hijo de Yocasta, sino que parte de las premisas que el destino tenía previstas para castigar, derrumbar y acabar con la progenie de Lábdaco, en cuyo caso el pueblo tebano era una víctima colateral con la pandemia sufrida. Hay que llamar la atención acerca del cambio que en la ficción mítica de un régimen monárquico a la tiranía, expuesto realmente en la democracia, adquiere en su representación poética la forma de la peste como metáfora de la enfermedad que tal proceso conlleva ${ }^{37}$ En las premisas del castigo de esta saga, Edipo no es más que la consecuencia última del destino funesto, pues sus hijos, su sangre fecundada en la misma sangre que lo parió, no tuvieron descendencia, por lo que la Erinia cierra el ciclo con la ley simbólica de que un delito de sangre sólo puede ser lavado con sangre:

Y estas cosas contra los que no atienden pido a los dioses, / que no les brote ninguna cosecha de la tierra, / ni hijos de sus mujeres, sino que por causa de su desgracia / presente y por una peor que ésta, perezcan. ${ }^{38}$

Si la sabiduría expuesta, entonces, es una mera condición prevista, se puede observar que Edipo no es verdaderamente el gobernante sabio que conduce a la polis de modo adecuado, pues, cuando se presenta el problema de la peste, este personaje no puede atar los cabos de su propio destino con el cual arrastra a Tebas al dolor y a la perdición. El tirano procede así: cuando más seguro está de que lo que hace y piensa es lo más correcto, es cuando más lejos se halla de la realidad concreta. Y no es que el pueblo sea sabio y se dé cuenta de ello. En el marco del Edipo tirano, sólo Tiresias sabe la verdad a fondo, mientras que Yocasta la va intuyendo poco a poco; el siervo de Layo, que vio que quien mató a éste fue Edipo, huyó cuando se percató de la llegada de éste para no tener que confrontar la terrible realidad. El pueblo tebano es la verdadera víctima de la ceguera de su gobernante a pesar de que la tragedia no enfoca su luz sobre él, pero es el que paga los errores de una

\footnotetext{
${ }^{37}$ Es relevante comprender cómo la tragedia griega, que se desarrolló a la par de la democracia, era depositaria de los mitos referidos a las grandes familias que parecen transitar los distintos sistemas de gobierno en la ficción trágica. Si atendemos lo que Herodoto atribuye a Darío sobre tales sistemas (III, 82, 1-5), bien se podría establecer un parangón con diversas tragedias del s. v, en especial Edipo tirano, y así observar la trama poética con un contenido aplicable a una teoría política. Cf. Scodel 1982,pp. 217-218.

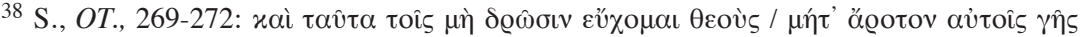

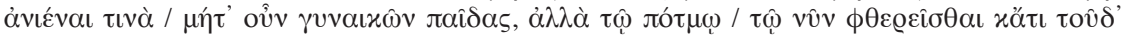
$\dot{\varepsilon} \chi \theta$ tíovl.
} 
familia que ha regido durante largos años y que ha venido heredando la desmesura (hybris). El Coro, reflejo de lo que los receptores reflexionan y eco de la generalidad popular, expone en la párodos la dimensión de la peste que azota a Tebas:

¡Ay de mí! Voy soportando dolores / innumerables: está enferma por completo mi gente y no hay una lanza de reflexión / con la que uno se pueda defender. Ni los frutos de la noble tierra crecen, ni de los partos / los lastimeros esfuerzos tienen que soportar las mujeres. / Y de uno en uno, cual rauda ave, puedes ver / que con más ímpetu que el fuego arrollador se precipitan / hacia la costa del dios de la oscuridad. ${ }^{39}$

Si bien es cierto que el término tyrannos era utilizado de modo general como un sinónimo neutro para referirse al rey (basileus), también lo es que la carga negativa era usual en el pensamiento político de la democracia ateniense, y si también es cierto que se ha dicho que Sófocles fue de los tres trágicos el que menos interés tuvo en representar asuntos políticos en sus tragedias, ${ }^{40}$ también lo es que tyrannos no debió de referirse a Edipo en la tragedia homónima como simple rey, sino que la connotación ideológica que se proyecta a través de una clara orientación política, a nuestro juicio, es evidente, haciendo de esta pieza trágica un texto reflexivo sobre las causas que llevan al tirano a gobernar en soledad y, por lo mismo, con un padecimiento trágico inexorable. El tirano por la boca muere, pero la soberbia es la soga que lo ata al destino fatal desde su nacimiento hasta su muerte.

Bañuls Oller explica que, de entre las múltiples perspectivas desde las cuales se puede analizar la tragedia y la comedia, la que "gira en torno al destino, entendido éste como el resultado de la relación dialéctica entre la acción del ser humano en el marco en el que la realiza y las fuerzas y principio que actúan en ese marco" es la de mayor trascendencia. ${ }^{41}$ En otras palabras, la historia se refleja en el género dramático del mismo modo como éste se mira en el espejo de los eventos humanos concretos. Así pues, Sófo-

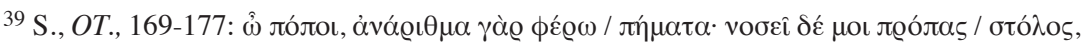

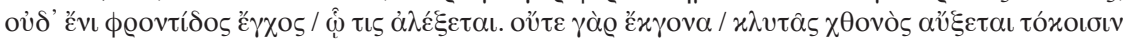

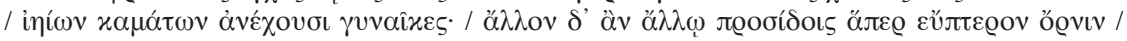

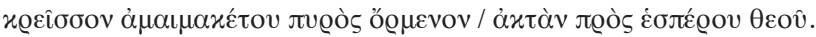

${ }^{40}$ Es oportuna la observación de Bañuls \& Morenilla 2009, p. 22: "Sófocles focaliza, pues, su mirada en el ser humano, en el individuo, en el marco comunitario por lo que en la caracterización de sus personajes, los aproxima a él, los hace más humanos, más próximos a los espectadores, a ese microcosmos que es la polis democrática, y a través de la contemplación de sus personajes, de sus héroes, advierte a sus conciudadanos de los peligros de una excesiva confianza en sí mismos y sus consecuencias en el uso de la libertad política, ya sea en un órgano colegiado [...], ya sea en un órgano unipersonal". Y el ejemplo en este último caso es Pericles, de acuerdo con Th., I, 139, 4, según apuntan Bañuls \& Morenilla.

${ }^{41}$ Bañuls 2016, pp. 53-54. 
cles fue testigo de la misma secuencia de hechos narrada por Tucídides en torno a la peste acaecida en Atenas y también consideró primordialmente al personaje histórico de ese momento, Pericles. Es posible considerar el discurso fúnebre de este estadista como un canto a la gloria de la democracia ateniense que enseguida se ve envuelta en una desgracia no prevista, inimaginable y muy dolorosa. La vida social como estaba concebida sufrió una metamorfosis repentina que se testimonia con la muerte misma de Pericles a causa de la peste. De un modo similar, en el plano de la ficción trágica, la Tebas de Edipo estaba en paz con la llegada de este nuevo gobernante que, además, había liberado a los tebanos de la terrible Esfinge. Y en el momento en el que todo parece ser prosperidad, la peste arranca de tajo los ojos del tirano, como metáfora suprema que le recuerda al individuo su naturaleza efímera y, sobre todo, su carácter propenso a la desmesura en todos los sentidos. Tragedia e historia muestran desde sus particulares miradas, a través de la epidemia, la fragilidad humana, la nada a la que se reduce la vida del individuo y la desmesura en la búsqueda misma de la felicidad. ${ }^{42}$

\section{BIBLIOGRAFÍA}

\section{Fuentes antiguas}

Apollodorus, The Library, vols. I y II, ed. James George Frazer, Cambridge, Harvard University Press, 1967 (1921).

Aristóteles, Política, intr., trad. y notas Manuela García Valdés, Madrid, Gredos, 1988.

Esquilo, Prometeo encadenado, intr., trad. y notas David García Pérez, México, Universidad Nacional Autónoma de México, 2013.

Herodoto, Historia, v. II, trad. y notas Carlos Schrader, Madrid, Gredos, 2015 (1982).

Hesíodo, Teogonía, intr., trad. y notas Paola Vianello, México, Universidad Nacional Autónoma de México, 2007 (1978).

Homero, Ilíada, ed. F. Javier Pérez, España, Abada, 2012.

Homero, Odisea, trad. José Manuel Pabón, Madrid, Gredos, 2000.

Hyginus, Fabulae, ed. Peter K. Marshall, München und Leipzig, K. G. Saur Verlag (Bibliotheca Teubneriana), 2002.

PíndARo, Odas y fragmentos, intr., trad. y notas Alfonso Ortega, Madrid, Gredos, 1984.

Sófocles, Tragedias, intr. José S. Lasso de la Vega, trad. y notas Assela Alamillo, Madrid, Gredos, 1981.

\footnotetext{
${ }^{42}$ Tal como lo expresa el Coro del Edipo tirano (vv. 1186-1195), luego de la anagnórisis del personaje central.
} 
Sophocles, The Plays and Fragments, v. 1: The Oedipus Tyrannus, notas críticas, com. y trad. R. C. Jebb, Cambridge, Cambridge University Press, 2010 (1883).

Sophocles, Oedipus the King; Oedipus at Colonus; Antigone, London \& New York, Macmillan, 1912.

SOPHOCLES, ed. G. Long, notas F. H. M. Blaydes, London, Whittaker, 1859.

Thucydides, Historiae, ed. H. Stuart Jones \& J. E. Powell, Oxford, Clarendon Press, 1942.

Tucídides, Historia de la Guerra del Peloponeso, intr., trad. y notas Juan José Torres Esbarranch, Madrid, Gredos, 2006 (1982).

\section{Fuentes modernas}

Alsina, José, “¿Un modelo literario de la descripción de la peste de Atenas?”, Emerita, 55-1, 1987, pp. 1-13, http://dx.doi.org/10.3989/emerita.1987.v55.i1.631.

Bañuls Oller, José Vicente, "Cuando la tragedia se hace historia y la historia tragedia", Noua Tellus, 34-2, 2016, pp. 53-87, http://dx.doi.org/10.19130/iifl. nt.2016.34.2.742.

Bañuls Oller, José Vicente \& Carmen Morenilla Talens, "Justicia y violencia en la tragedia de Sófocles", Carmen Morenilla Talens \& Francesco de Martino, Legitimación e institucionalización política de la violencia, Bari, Levante editori, 2009, pp. 17-64.

Detienne, Marcel, "Being Born Impure in the City of Cadmus and Oedipus", Arion, 10-3, 2003, pp. 35-47.

Jounnna, Jacques, Greek Medicine from Hippocrates to Galen, Leiden \& Boston, Brill, 2012, http://dx.doi.org/10.1163/9789004232549.

KERÉNYI, Karl, Los héroes griegos, trad. Cristina Serna, Barcelona, Atalanta, 2009.

Knox, B. M. W., "Why is Oedipus called Tyrannos?", CJ, 50, 3, 1954, pp. 97-102, 130, http://dx.doi.org/10.4324/9780203055892-6.

Scodel, Ruth, "Hybris in the Second Stasimon of the Oedipus Rex", CPh, 77-3, 1982, pp. 214-223, http://dx.doi.org/10.1086/366711.

Segal, Charles, Oedipus Tyrannus: Tragic Heroism and the Limits of Knowledge, New York, Twayne, 1993.

$$
* * *
$$

David García Pérez es doctor en Letras Clásicas por la Universidad Nacional Autónoma de México; es investigador titular en el Centro de Estudios Clásicos del Instituto de Investigaciones Filológicas y profesor definitivo de Literatura Griega I y II en la Facultad de Filosofía y Letras de la UnAm; profesor y tutor del Posgrado en Letras y de la Maestría en Docencia para la Educación Media Superior (áreas de español y de Letras Clásicas); ha sido director de la revista Noua Tellus en dos ocasiones. Miembro del Sistema Nacional de Investigadores desde el año 2000. Líneas de investigación: teatro clásico griego y literatura comparada. 